\title{
The Cloud Medical Science Classroom System Based on Human Skeleton
}

\author{
Deng-Yang Huang
}

\begin{abstract}
This study aimed to design a system called "cloud classroom for medical science” for anatomy, a basic medical science subject, based on related literature, in order to resolve the issues related to medical science personnel cultivation and learning effects. Then technologies related to multimedia, smart phones, tablet computers, cloud computing, Arduino, and RFID were integrated to develop a set of teaching materials and aids which even children can understand and use easily. It is hoped that this system can help efficiently remove barriers to medical science knowledge, so that this knowledge is no longer knowledge which can only be learned after secondary education.
\end{abstract}

Index Terms-Medical science, anatomy, digital learning, medical science teaching aids.

\section{INTRODUCTION}

Medical science is a science dealing with health. The main purpose is to take preventive measures and to maintain physical and mental health. This science can influence people's life in all aspects. Anatomy is the most basic and important subject in medical science. To master human body's physiological conditions and pathological changes, clear understanding of human body structure is essential. Without this understanding, it is impossible to correctly diagnose abnormal pathological conditions of a human body, not to say to identify diseases and perform proper treatments. Thus, learning about the structures of all the human body organs is a required foundation before learning other medical science subjects and clinical medicine.

The teaching material for the anatomy course contains 10 chapters (skeletal system and muscular system, skin, nerves system, endocrine system, circulatory system and lymph, respiratory system, urinary system, digestive system, reproductive system, and immune system). The topic of each chapter is an independent major subject. The basic learning method is to get familiar with the content and memorize it. This method looks simple and doesn't require logical thinking. Yet, learners always have difficulties using this method. The main reasons are as below:

1) The content to be learned is too broad. Moreover, content related to clinical works is presented in the original text. Yet, many proper nouns are Greek or Latin words. The corresponding knowledge is vast and complex. Even senior medical personnel can hardly learn everything.

Manuscript received May 20, 2016; revised January 15, 2017.

Deng-Yang Huang is with the Department of Information Management, Yuanpei University of Medical Technology, Hsinchu,Taiwan, R.O.C. (e-mail: dyhung@mail.ypu.edu.tw).
2) Learners in medical or nursing departments are always memorizing medical proper nouns. However, medical text books are all heavy and big with dense typesetting. It is very inconvenient for learners to look up something while learning.

3) Learners don't have sufficient time for after-class review. What they had learned in class is easily forgotten.

4) Traditionally, medical and nursing teaching is teacher-centered. Courses are designed for content teaching [1]. And the main teaching method is lecturing. There are very few teacher-student interactions. Performances are usually evaluated based on exams with test papers. Teachers don't know what problems learners have encountered.

5) In this advanced society with easy-to-get information, learners can now obtain more and richer information. There are all kinds of seducers such as games and social networks. It is very easy for learners to find a class boring and dull, resulting in low interest in learning and low willingness to learn.

The research purposes of this study are summarized below:

1) This study aimed to build a systematic learning system, a tool which offers a quick search function and information of the correct pronunciations of medical terms, and physical teaching aids to create real scenarios, helping learners to learn the content they might easily miss and aspects which require more efforts. This study provides a solution to retrieve professional medical knowledge.

2) This study aimed to develop a teaching system, which can provide medical knowledge and course content through portable smart devices such as smart phones and tablet computers. With this solution, learners can look up information and review course content any time anywhere.

3) This study aimed to increase learners' interest in learning. Teachers and students can, through the system platform and physical teaching aids, perform interactive learning and exams. This system helps to enhance learners' impression for the professional medical knowledge they have learned from the system.

4) This study aimed to provide complete records of learners' learning conditions, so that learners can find out their learning conditions and make corresponding adjustments, and teachers can offer individual guidance based on their students' learning conditions. As a result, there would be more close interactions between teachers and learners.

5) This study aimed to design a system based on games, in order to increase learners' interest in learning and 
willingness to learn. It requires interactive and cooperative games to transform the traditional method of lecturing into learners' self-learning on their own initiative.

This study designed an interactive e-learning platform with some physical teaching aids for learners to learn. The main purpose is to increase learners' learning efficiency. Although in the market there are a lot of teaching tools, only very few of them can integrate multimedia and physical teaching aids. Learners can study issues and identify rules on their own instead of learning everything from their teachers' lecturing. Web pages and mobile devices were integrated with the teaching materials to improve interactions.

\section{BACKGROUND}

The section of related theories and literature review of this study mainly discussed issues such as e-learning, teaching models, and learning effects. The theories which formed the fundamental structure of this study and their descriptions are summarized below:

\section{A. The Influence of E-Learning on Teaching}

The internet has become a part of modern people's life. Information inquiry and even entertainment can be done through the internet. In this age of knowledge explosion, e-learning can perfectly meet the demand for creative knowledge with the feature of being available any time anywhere.[2] It can break the geographic barrier to improve learning effect. This, in the 21st century, it has been implemented and we'll developed. And the development of mobile devices has increased the possibility of e-learning.

\section{B. The Current Status of E-Learning Applications}

The development of e-learning has changed human beings' learning environments and methods. One of the features of e-learning is that, with the help of information technology, there is no time or location related constraint on users' learning. According to the 2012 "global e-learning market” report by Ambient Insight, the size of the global market of teaching materials with e-learning content, platform tools, and learning services would reach 41.2 billion US dollars in 2013, and 51.5 billion in 2016, with the CAGR being $7.6 \%$. In the recent years, with the rapid growth of mobile application stores, applications have become essential tools in consumers' daily life. Educational applications have been used in more and more fields.[3] With diversified integration of digital content, some game applications also contain educational content. As a result, the market has become a newly rising market in the recent years and all related vendors want a piece of it. Examples of applications include educational institution network and smart classroom. Now, the focus is on digitalization of teaching materials and active efforts to facilitate cooperation between distributors and large technology companies. The effects and influences of e-learning are being enhanced and extended through games and clouds.

\section{The Benefits the ARCS Model Brings to Teaching}

In 1983 J. M. Keller [4] proposed the ARCS model.
“ARCS” is the short for attention, relevance, confidence, and satisfaction, the four elements. It is a motivation model based on the teaching design model to inspire learners' learning motivation and integrated with the motivation theory and other related theories. Traditional teaching designs care less about learners' learning motivation. If the teaching materials developed for any one teaching design cannot get learners' attention or make them interested, the learning effects of that teaching design would be less than expected. Thus, if teaching design strategies can be based on learners' motivational demands in order to inspire their learning motivation, their learning performances can be efficiently improved.

\section{The Integration of Clouds, Social Groups, and Games}

With the government's active promotion and the guidance of the future trend, plus the rapid development of the internet, synchronous and asynchronous teaching systems have been developed. In the future, hardware and software costs in promotion of information education and e-learning can be greatly reduced. Modern students have access to much richer information due to the advancement of information technology. It is obvious that the thoughts and concepts are very different between this generation and the previous one. [5] Nowadays, when students sit in a classroom, they are asked to sit quietly and listen to their teacher's lecturing. However, the life outside the classroom is filled with all kinds of seducers, such as games and social networks. It is not at all surprising that students would find classes they attend boring and dull.

According to the above description, if the advantages of multimedia e-teaching and the popularization of information technology can be integrated by designing an interactive multimedia learning strategy, it is possible that more learners will attend classes and benefit from them. This way, a ubiquitous quality learning environment can be built to improve learning effects so that when students fined a field work after graduation, they can master it in a short time.

\section{SySTEMS ARCHITECTURE}

This study designed the system for two types of users, teachers and learners. When a learner uses the system, he can carry on interactive learning through the two major platforms with physical teaching aids and the system will automatically record his learning conditions and provide a summary of the records through the computing cloud to the learner to check his own learning conditions and his teacher to find out the learner's learning conditions in order to offer proper guidance.

The system structure contains three layers. All the system components were from cloud components. Thus, in the designing and developing process, there is no need for programming for each application platform. All that needed to be done was to rearrange the operation interfaces. This is a rather efficient way for software development. In this system, there are a lot of data of multimedia content, professional medical terms, English pronunciations, and skeletal structure associations, which are all stored on the data cloud. Based on these data, a computing cloud was designed to offer services 
such as learning effect presentation, real-time exams, and individual learner condition review, through both the web platform and the mobile device platform. This design also allows future extension.

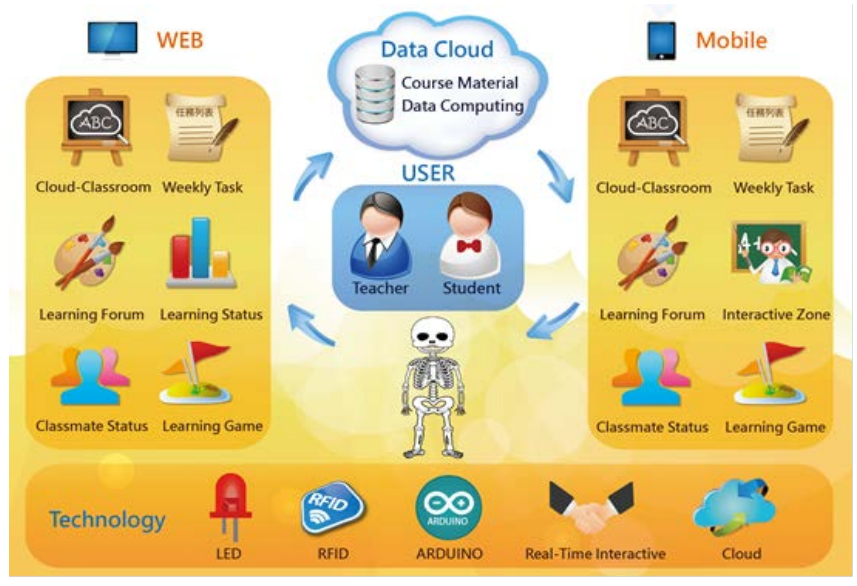

Fig. 1. The cloud medical science classroom system architecture.

\section{IMPLEMENTATION}

This study combined the platform for smart phones and tablet computers and the web platform with the physical teaching aids such as RFID, Arduino, and LED to interact with learners. As shown in the figure, the two main application platforms are the platform for hand-held devices and the web platform. The "cloud classroom for medical science" was built on both platforms for the purpose of improving learners' learning effects. This is the research direction of this study.

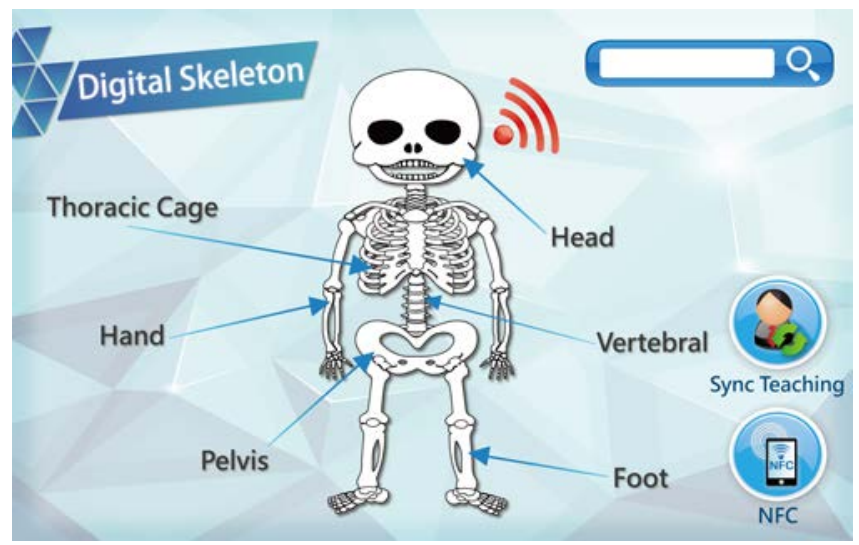

Fig. 2. The mobile device platform.

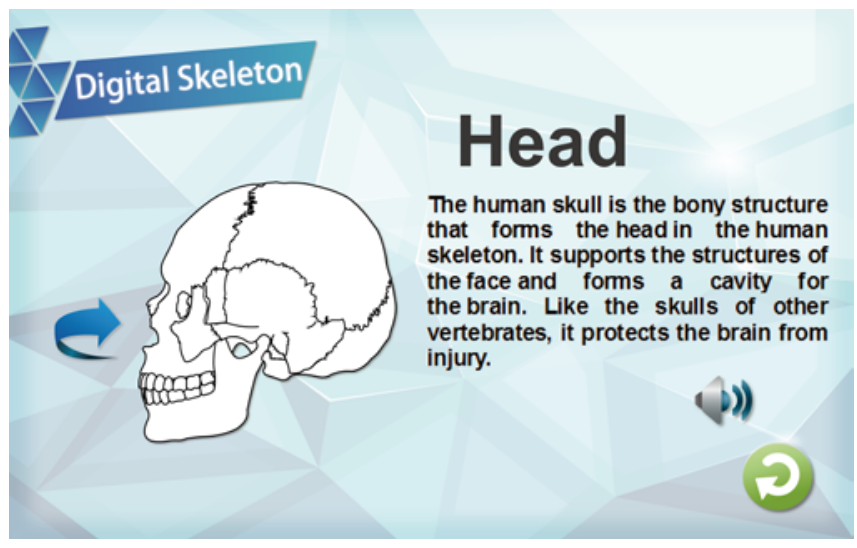

Fig. 3. The details of skeleton.
The system structure contains two main platforms, the web platform (Web) and the mobile device platform (APP). Based on the concept of social groups and the method of playing games, this system can increase users' interest. Through the cloud technology, the two main platforms can be combined with physical teaching aids so that users can learn more about the skeletal structure. The indicators were designed based on the ARCS (attention, relevance, confidence, and satisfaction) model. RFID tags were placed on 206 bones. Through the Arduino technology, the mobile device platform (APP) and the web platform (Web) were combined. The use of the cloud technology largely increases the range of applications. As long as there is internet access, one can learn easily. This system offers different functions for different users and user scenarios. The functions of the "cloud classroom for medical science: skeletal system as an example” are as below:

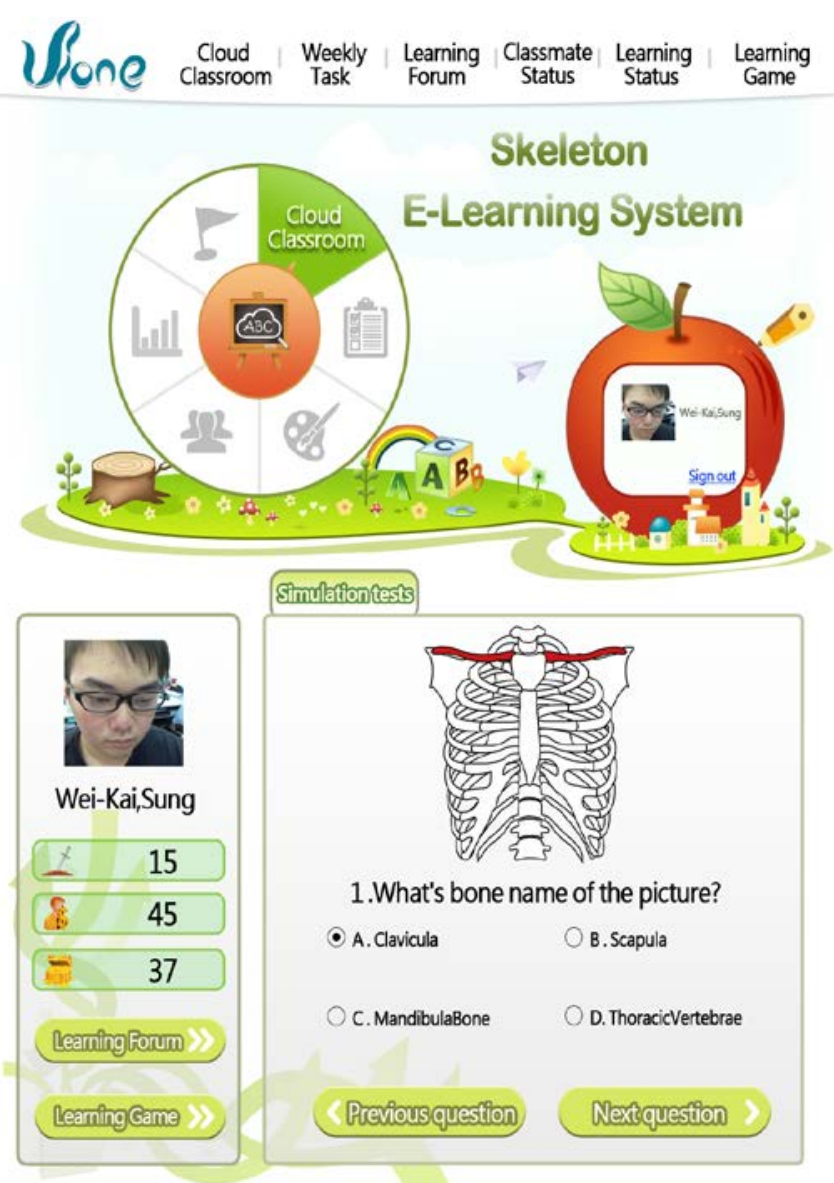

Fig. 4. The exams of skeleton system.

Teachers can make out questions using the web interface, and students can perform a human body skeleton scan using the RFID tags or simply clicking on the bones displayed on the screen to answer these questions. e-skeleton: It is an online teaching for the skeletal system. Users can use keyword search to find a certain bone or find it based on the six parts.

The cloud classroom offers three functions: e-skeleton, simulation test, and real-time Q\&A. The NFC technology can be applied to all three functions. Students can scan the RFID tags on the bones, or they can click on the bones on the screen for learning, taking exams, and answering their teacher's questions. Students can participate in exams any time anywhere. 


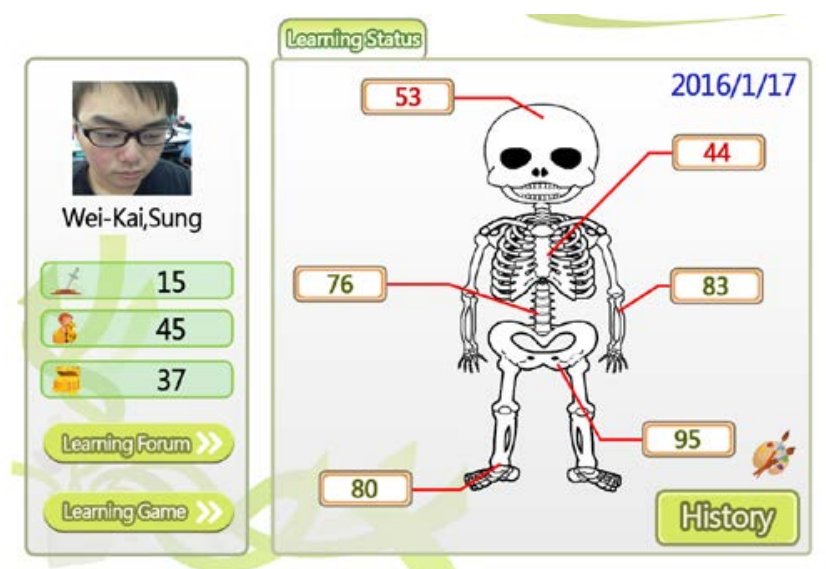

Fig. 5. The score of skeleton exam.

Students can click on any of the bones to see details for learning. By clicking on the synchronization button on the right side the content displayed on the screen will be synchronized with what the teacher is currently teaching. By clicking the NFC button on the lower right, the RFID tags on the physical bones will be engaged to display corresponding information, as shown in the figure.

\section{CONCLUSION}

The focus of this study is on the platform integrating information and medical science. With technologies such as cloud computing, cloud storage, RFID, and Arduino, learning methods for students can be more diversified. The system developed by this study has been implemented in the medical related departments in our university. Thus, when developing the "cloud classroom for medical science", this study also used the system to research the benefits brought to students by e-learning. Through this system, the data of students' performances after using this system and their feedbacks were collected for analyses and evaluations. The conclusions summarized can be used as a reference for the academic circle.

\section{ACKNOWLEDGMENT}

This research is supported by the Ministry of Science and Technology of the republic of China Contract No. MOST 104-2511-S-264-001-MY2.

\section{REFERENCES}

[1] RL. Kneebone, W. Scott and A. Darzi, "Simulation and clinical practice: strengthening the relationship,” Med Educ, vol. 38, pp. 1095-1102, 2004.

[2] RL. Kneebone, "Clinical simulation for learing procedural skills: A theory-based approach,” Acad Med, vol. 80, pp. 549-553, 2005.

[3] R. Kneebone, "Perspective: simulation and transformational change: The paradox of expertise," Acad Med.vol. 84, pp. 954-957, 2009.

[4] J. M. Keller, "Development and use of the ARCS model of motivational design," Journal of Instructional Development, 1987.

[5] FB. Hannon, "A national medical education needs assessment of interns and the development of an intern education and training programme,” Med Educ, vol. 34, pp. 275-284, 2000.

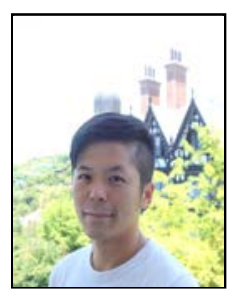

Deng-Yang Huang is currently an associate professor in the Department of Information Management at Yuanpei University of Medical Technology and had served as a certified Lecturer of the Oracle Training Service Department and the chief of the Information Networking division and the System Programming division at Yuanpei University of Medical Technology. Huang had been received by the Vice President of Taiwan (R.O.C.), the President of the Legislative Yuan, and the Deputy Minister of the Ministry of Education. His research fields include medical information, ubiquitous computing, and green cloud computing. He is also an expert in technical fields including Java EE, Android, C\#.NET, cloud application development, object-oriented software structure, etc. He had been the lecturer for the Java Certification Day 2009, Java Certification Day 2010, and Microsoft TechNet. He is a MCT (Microsoft certified trainer) and a SAI (Sun authorized instructor) and he has over 10 other international certificates. For 9 consecutive years, there had been students guided by him participating in various competitions, including Seoul International Invention Fair, Invention Innovation and Technology Exhibition in Malaysia, Trend Micro Cloud App Programming Competition, CHT Telecommunication Innovative Application Competition, Microsoft Imagine Cup, International ICT Innovative Services Awards, and many other competitions, and brining home prizes. 